\title{
PENTINGNYA PENDIDIKAN NILAI MORAL \\ BAGI GENERASI PENERUS
}

\author{
Ahmad Nawawi \\ Jurusan PLB FIP UPI Bandung
}

\begin{abstract}
Moral/ Religion Values Education in Indonesia from 1968 to nowadays are still neglected, it has not been addressed in a planned and serious. This is proved by the number of hours learning that has nuances of religious and moral education in minimal, it is only 2 to 4 hours per week than the hours from 34 to 42 hours per week. Whereas by KTSP, it is actually more manageable, so that these needs can be accommodated and fulfilled.

Moral/ Religion Values Education is very important for youth as the future generation, that lifted the nation's dignity, increasing quality of life, life for the better, safe and comfortable and prosperous. Education is to form the next generation who has German brains and has Mecca heart that reflects a balance between knowledge and practice of the moral / religious values.

Ideal conditions of the next generation youth, as an individual who is growing, and therefore need to be given the opportunity to grow in proportion, directed, and optimal and get a balanced education services between knowledge and moral / religion education. They have a role and position strategic in the continuity of the nation life. But the factual conditions in the field as it appears in print and electronic media, in fact as the next generation, youths caught up in immoral behavior that is very worrying and fearing even disturbing the public, such as the emergence of biker gangs, fights (students, university students, and even between villages involving mass ). It is predicted as a result of the neglect of Moral Values Education in Indonesia. Therefore, this writing tries to explore based on literature review and the real conditions in the field to obtain a reliable solution / cespleng. Assisted by the Social and Moral Development theories of Albert Bandura and Kohlberg expected a solution to encourage the implementation of Moral/ Religion Values Education in Indonesia. Keywords: Moral Values Education / Religion, next generation.
\end{abstract}




\section{Pendahuluan}

Apabila kita melihat dari sudut pandang psikologi perkembangan, dunia nampak semakin tua, manusia semakin cerdas, pengetahuan semakin dewasa, dan teknologi pun semakin canggih. Namun di balik semua itu, apakah kehidupan kita menjadi semakin baik, semakin nyaman, dan semakin sejahtera baik secara lahiriah maupun bathiniah? Mungkin tidak, bahkan sebaliknya. Kehidupan kita nampaknya semakin mundur dan terpuruk, reformasi kita gebablasan, korupsi semakin terang-terangan dan merajalela, krisis multi dimensi pun tak kunjung selesai. Bangsa ini nampaknya sudah cukup lelah melihat, menyaksikan dan mengalami keadaan yang demikian. Seperti dikemukakan oleh Dedi Supriadi (Pikiran Rakyat, 12 Juni 2001: 8-9), bahwa orde baru berakhir, dan muncul era reformasi. Era ini menyaksikan sosok bangsa ini yang lunglai, terkapar dalam ketidak berdayaan akibat berbagai krisis yang dialaminya.

Keadaan tersebut tidak saja mengakibatkan terpuruknya ekonomi, tetapi juga mengakibatkan merosotnya kualias hidup, bahkan merosotnya martabat bangsa. Apakah gerangan yang menyebabkan semua itu? Kalau kita telaah mungkin akan muncul sederetan faktor penyebab. Ada yang mengatakan karena pejabatnya tidak jujur, korup, penegak hukumnya tidak adil, rakyatnya tidak produktif, karyawan bawahannya tidak loyal, tidak bisa kerjasama, tidak empati, tidak mempunyai keteguhan hati dan komitmen, pelajar dan mahasiswanya tawuran, dan sebagainya.

Kalau kita simak dari uraian di atas, faktor penyebab utamanya adalah masalah nilai moral, sekali lagi nilai moral. Mungkinkah nilai moral sudah hilang di Negara kita? Mungkinkah nilai moral sudah tidak dimiliki oleh generasi penerus bangsa? Seperti dikatakan oleh Pam Schiller dan Tamera Bryant (2002: viii), bahwa jika kita meninggalkan pelajaran tentang nilai moral yang kebanyakan sudah berubah, kita, sebagai suatu Negara, beresiko kehilangan sepotong kedamaian dari budaya kita. Timbullah pertanyaan, apakah pelajaran tentang nilai moral di Negara kita selama ini telah diabaikan? Menurut Dedi Supriadi, pendidikan budi pekerti dan pendidikan agama pada saat itu (1968-1980-an) dapat dikatakan 'terpinggirkan' oleh haru-biru semangat Pendidikan Moral Pancasila. Bagaimana pada tahun 1990-2000-an sampai sekarang? Apakah pendidikan budi pekerti dan pendidikan agama masih juga terabaikan? 
Berdasarkan uraian di atas dapat ditarik kesimpulan bahwa satu penyebab krisis multi dimensi, termasuk krisis moral yang menimpa bangsa kita adalah karena telah terabaikannya "pendidikan moral" (dalam pengertian pendidikan agama, budi pekerti, akhlaq, nilai moral) bagi generasi penerus. Betapa tidak, ajaran agama mengatakan: “Carilah untuk kehidupan duniamu seolah-olah kamu akan hidup selamanya, dan carilah akhiratmu seolah-olah kamu akan mati besok pagi". Allah pun berfirman dalam al Qur'an: "Barang siapa menginginkan dunia maka raihlah dunia itu dengan ilmu, dan barangsiapa menginginkan akhirat maka raihlah dengan ilmu pula".

Dalil tersebut di atas mengandung makna bahwa dalam studi ilmu pengetahuan umum dan agama hendaklah seimbang, "fiddunya khasanah wa fil akhirati khasanah". Ini jelas Islam mengajarkan dan menyuruh kepada pemeluknya untuk berotak Jerman-berhati Mekah, demi mencapai kesejahteraan hidup di dunia ini dan akhirat nanti. Dengan demikian, kalaulah di SD, SMP, atau SMU terdapat 36 jam pelajaran perminggu, setidaknya terdapat 18 jam untuk ilmu pengetahuan umum dan 18 jam untuk agama (semua agama), atau paling tidak 20 jam pelajaran untuk pengetahuan umum dan 16 jam untuk agama (pendidikan nilai moral). Sedangkan yang ada dari dulu sampai sekarang komposisinya adalah 34 jam pelajaran untuk pengetahuan umum dan 2 jam atau paling banyak 4 jam untuk pendidikan agama, dari TK sampai Perguruan Tinggi.

Jadi, dengan hanya 4 jam pelajaran perminggu anak sebagai generasi penerus mendapatkan apa? Iman yang kuat? Agama yang kokoh? Moral yang tinggi? Akhlak mulia? Dapat dipastikan tidak! Barangkali hanya mendapatkan kulitnya saja, dan tidak tau isinya. Akhirnya agama hanya dibibir, belum menjadi penghayatan dan pengamalan. Orang yang mengaku beragama tetapi tidak pernah mengamalkannya, ia bagaikan memiliki garam satu truk tetapi tidak pernah tahu rasa asinnya, punya gula satu peti kemas tetapi tidak pernah tau rasa manisnya.

Inilah gambaran generasi penerus kita. Tak ayal lagi nilai-nilai moral/ agama tidak tertanam dan tidak dimilikinya oleh anak didik kita, kecuali hanya sangat sedikit. Apa akibatnya? Ketika mereka menginjak bangku SMP sudah mulai tawuran, menginjak SMA mendapatkan julukan SMA tawuran, dan ketika mereka menduduki bangku kuliah, apa yang terjadi. 
Kalau mereka menjadi mahasiswa, mungkin akan menjadi mahasiswa yang agresif, pemberani, pendemo dan tukang tawuran. Kalau kelak mereka menjadi pejabat, mungkin tidak jujur dan korup. Inikah moral mereka?

Pendidikan nilai moral/agama sangat penting bagi tegaknya satu bangsa. Tanpa pendidikan nilai moral (agama, budi pekerti, akhlak) kemungkinan besar suatu bangsa bisa hancur, carut marut. Munculnya kembali pendidikan budi pekerti sebagai primadona dewasa ini mencerminkan kegusaran bangsa ini akan terjadinya krisis moral bangsa dan kehidupan sosial yang carut marut. (Dedi Supriadi, Pikiran Rakyat 12 Juni: 8-9).

Pam Schiller dan Tamera Bryant (2001: vii) mengemukakan inilah waktunya untuk menentukan apakah nilai-nilai moral penting bagi masa depan anak-anak kita dan keluarga kita, dan kemudian mendukung dan mendorong mereka mempraktikkan nilai-nilai moral tersebut dalam kehidupan sehari-hari. Siapa yang bertanggung-jawab untuk mengajarkan nilai-nilai moral ini pada anak-anak kita? Tanggung-jawab itu dipikul oleh kita semua. Apakah kita menyadari atau tidak, kita selalu mengajarkan nilai moral, tetapi kita harus lebih berusaha keras untuk mengajarnya. Nilai-nilai moral yang kita tanamkan sekarang, sadar atau tidak sadar, akan mempunyai pengaruh yang sangat besar pada masyarakat yang akan datang.

\section{Tinjauan Teoretis}

Apakah pendidikan nilai moral itu? Pendidikan dalam arti yang luas meliputi semua perbuatan dan usaha dari generasi tua untuk mengalihkan pengetahuannya, pengalamannya, kecakapannya serta keterampilannya kepada generasi muda sebagai usaha menyiapkannya agar dapat memenuhi fungsi hidupnya baik jasmaniah maupun rohaniah (Soegarda Poerbakawaca dan Harahap, H.A.H., 1981: 257).

Menurut Undang-Undang Sistem Pendidikan Nasional tahun 2003 pasal 1 ayat (1): "Pendidikan adalah usaha sadar dan terencana untuk mewujudkan suasana belajar dan proses pembelajaran agar peserta didik secara aktif mengembangkan potensi dirinya untuk memiliki kekuatan spiritual keagamaan, pengendalian diri, kepribadian, kecerdasan, akhlak mulia, serta keterampilan yang diperlukan dirinya, masyarakat, bangsa dan negara." 
Sedangkan "nilai" merupakan suatu ide - sebuah konsep - mengenai sesuatu yang dianggap penting dalam kehidupan. Ketika seseorang menilai sesuatu, ia menganggap sesuatu tersebut berharga untuk dimiliki, berharga untuk dikerjakan, atau berharga untuk dicoba maupun untuk diperoleh. Studi tentang nilai biasanya terbagi ke dalam area estetik dan etik. Estetik berhubungan erat dengan studi dan justifikasi terhadap sesuatu yang dianggap indah oleh manusia, apa yang mereka nikmati. Etik merupakan studi dan justifikasi dari tingkah laku - bagaimana orang berperilaku. Dasar dari studi etik adalah pertanyaan mengenai moral - yang merupakan suatu refleksi pertimbangan mengenai sesuatu yang dianggap benar atau salah (Jack R. Fraenkel, 1977: 6). Moral menurut kamus Poerwadarminta (1989: 592), adalah ajaran tertentu baik buruk yang diterima umum mengenai perbuatan, sikap, kewajiban; akhlak, budi pekerti, susila.

Menurut Soegarda P. dan Harahap, H.A.H. (1981: 434), ciri-ciri yang menunjukkan adanya pendidikan moral: (1) cukup memperhatikan instink dan dorongan-dorongan spontan dan konstruktif; (2) cukup membuka kondisi untuk membentuk pndapat yang baik; (3) cukup memperhatikan perlunya ada kepekaan untuk menerima dan sikap responsif; (4) pendidikan moral memungkinkan memilih secara bijaksana mana yang benar, mana yang tidak.

Jadi pendidikan nilai moral adalah suatu usaha sadar yang dilakukan oleh manusia (orang dewasa) yang terencana untuk memberikan kesempatan kepada peserta didik (anak, generasi penerus) menanamkan keTuhanan, nilai-nilai estetik dan etik, nilai baik dan buruk, benar dan salah, mengenai perbuatan, sikap dan kewajiban; akhlak mulia, budi pekerti luhur agar mencapai kedewasaannya dan bertanggung jawab.

Adapun ruang lingkup materi pendidikan nilai moral antara lain meliputi: ke-Tuhanan, kejujuran, budi pekerti, akhlak mulia, kepedulian dan empati, kerjasama dan integritas, humor, mandiri dan percaya diri, loyalitas, sabar, rasa bangga, banyak akal, sikap respek, tanggung jawab, dan toleransi (Pam Schiller dan Tamera Bryant, 2002), serta ketaatan, penuh perhatian, dan tahu berterima kasih. 


\section{Teori Pendidikan Nilai Moral}

Pendidikan nilai moral ini didukung oleh beberapa teori perkembangan, antara lain teori perkembangan sosial dan moral siswa yang dikemukakan oleh Lawrence Kohlberg dan Albert Bandura.

- Teori Perkembangan Pertimbangan Moral Kohlberg

Lawrence Kohlberg adalah pengikut Piaget, menemukan tiga tingkat perkembangan moral yang dilalui para remaja awal, masa remaja, dan pasca remaja. Setiap tingkat perkembangan terdiri atas dua tahap perkembangan, sehingga secara keseluruhan perkembangan moral manusia terjadi dalam enam tahap.

Menurut Kohlberg perkembangan sosial dan moral manusia terjadi dalam tiga tingkatan besar yaitu: (a) tingkatan moralitas prakonvensional, yaitu ketika manusia berada dalam fase perkembangan remaja awal, yang belum menganggap moral sebagai kesepakatan tradisi sosial; (b) tingkat moralitas konvensional, yaitu ketika manusia menjelang dan mulai memasuki fase perkembangan masa remaja, yang sudah menganggap moral sebagai kesepakatan tadisi sosial; (c) tingkat moralitas pascakonvensional, yaitu ketika manusia telah memasuki fase perkembangan masa remaja dan pasca remaja (usia 13 tahun ke atas), yang memandang moral lebih dari sekedar kesepakatan tradisi sosial.

Untuk lebih jelasnya kita lihat table di bawah ini:

Enam Tahap Perkembangan Pertimbangan Moral Kohlberg

\begin{tabular}{|c|c|c|}
\hline TINGKAT & TAHAP & KONSEP MORAL \\
\hline Tingkat I & $\begin{array}{l}\text { Moralitas } \\
\text { prakonvensional (usia } \\
\text { 4-10 tahun) } \\
\text { Tahap 1: } \\
\text { Memperhatikan ketaatan } \\
\text { dan hukum } \\
\text { Tahap 2: } \\
\text { Memperhatikan } \\
\text { pemuasan kebutuhan }\end{array}$ & $\begin{array}{l}\text { Anak menentukan keburukan } \\
\text { berdasarkan tingkat hukuman } \\
\text { akibat keburukan tersebut; } \\
\text { Perilaku baik dihubungkan } \\
\text { dengan penghindaran diri dari } \\
\text { hukuman; } \\
\text { Perilaku baik dihubungkan } \\
\text { dengan pemuasan keinginan } \\
\text { dan kebutuhan sendiri tanpa } \\
\text { mempertimbangkan kebutuhan } \\
\text { orang lain. }\end{array}$ \\
\hline
\end{tabular}




\begin{tabular}{|c|c|c|}
\hline Tingkat II & $\begin{array}{l}\text { Moralitas konvensional } \\
\text { (usia 10-13 tahun) } \\
\text { Tahap 3: } \\
\text { Memperhatikan citra } \\
\text { "anak baik" } \\
\text { Tahap 4: } \\
\text { Memperhatikan hukum } \\
\text { dan peraturan }\end{array}$ & $\begin{array}{l}\text { Anak dan remaja berperilaku } \\
\text { sesuai dengan aturan dan } \\
\text { patokan moral agar memperoleh } \\
\text { persetujuan orang dewasa, bukan } \\
\text { untuk menghindari hukuman; } \\
\text { Pebuatan baik dan buruk dinilai } \\
\text { berdasarkan tujuannya. Jadi, } \\
\text { ada perkembangan kesadaran } \\
\text { terhadap perlunya aturan. } \\
\text { Anak dan remaja memiliki sikap } \\
\text { pasti terhadap wewenang dan } \\
\text { peraturan; } \\
\text { Hokum harus ditaati oleh semua. }\end{array}$ \\
\hline Tingkat III & $\begin{array}{l}\text { Moralitas } \\
\text { pascajonvensional (usia } \\
\text { 13 tahun ke atas) } \\
\text { Tahap 5: } \\
\text { Memperhatikan hak } \\
\text { perseorangan. }\end{array}$ & $\begin{array}{l}\text { Remaja dan dewasa } \\
\text { mendefinisikan (mengartikan) } \\
\text { perilaku baik sebagai hak pribadi } \\
\text { sesuai dengan aturan dan patokan } \\
\text { sosial; } \\
\text { Perubahan hukum dan aturan } \\
\text { dapat diterima jika diperlukan } \\
\text { untuk mencapai hal-hal yang } \\
\text { paling baik; } \\
\text { Pelanggaran hokum dan aturan } \\
\text { dapat terjadi karena alasan-alasan } \\
\text { tertentu. } \\
\text { Keputusan mengenai prilaku } \\
\text { sosial didasarkan atas prinsip } \\
\text { moral pribadi yang bersumber } \\
\text { dari hukum universal yang } \\
\text { selaras dengan kebaikan umum } \\
\text { dan kepentingan orang lain; } \\
\text { Keyakinan terhadap moral } \\
\text { pribadi dan nilai-nilai tetap } \\
\text { melekat meskipun sewaktu- } \\
\text { waktu berlawanan dengan hukum } \\
\text { yang dibuat untuk mengekalkan } \\
\text { aturan sosial. }\end{array}$ \\
\hline
\end{tabular}




\section{Ahmad Nawawi}

- Teori Belajar Sosial dan Moral Albert Bandura

Prinsip dasar belajar hasil temuan Bandura meliputi proses belajar sosial dan moral. Menurut Bandura sebagian besar dari yang dipelajari manusia terjadi melalui peniruan (imitation) dan contoh perilaku (modeling). Anak mempelajari respon-respon baru dengan cara pengamatan terhadap perilaku model/contoh dari orang lain yang menjadi idola, seperti guru, orang tua, teman sebaya, dan atau insane film yang setiap saat muncul di tayangan televise.

Pendekatan teori belajar sosial terhadap proses perkembangan sosial dan moral siswa ditekankan pada perlunya conditioning (pembiasaan merespon) dan imitation (peniruan). Proses internalisasi atau penghayatan siswa terhadap moral standarts (patokan-patokan moral) terus terjadi. Imitasi atau peniruan terhadap orang tua, guru, teman idola, dan insane film memainkan peran penting sebagai seorang model atau tokoh yang dijadikan idola atau contoh berperilaku sosial dan moral bagi siswa (generasi penerus).

Untuk lebih jelasnya kita lihat table di bawah ini:

Perbandingan antara teori perkembangan sosial dan moral Bandura dan Kohlberg:

\begin{tabular}{|l|l|l|}
\hline ASPEK & ALBERT BANDURA & LAWRENCE KOHLBERG \\
\hline Tekanan dasar & $\begin{array}{l}\text { Perilaku } \\
\text { Bergantung pada } \\
\text { orang lain dan kondisi } \\
\text { stimulus }\end{array}$ & $\begin{array}{l}\text { Pemikiran } \\
\text { Sebagai perilaku kualitatif } \\
\text { dalam perkembangan }\end{array}$ \\
\hline $\begin{array}{l}\text { Mekanisme } \\
\text { perolehan } \\
\text { moralitas }\end{array}$ & $\begin{array}{l}\text { Hasil dari conditioning } \\
\text { dan modeling }\end{array}$ & $\begin{array}{l}\text { Berlangsung pada tahap-tahap } \\
\text { yang teratur dan berkaitan } \\
\text { dengan perkembangan } \\
\text { kognitif moralitas }\end{array}$ \\
\hline Usia perolehan & $\begin{array}{l}\text { Belajar berlangsung } \\
\text { sepanjang hayat, dan } \\
\text { ada perbedaan usia } \\
\text { perolehan }\end{array}$ & $\begin{array}{l}\text { Proses belajar } \\
\text { berkesinambungan sampai } \\
\text { masa dewasa, dan juga dapat } \\
\text { ditetapkan dalam usia-usia } \\
\text { tertentu }\end{array}$ \\
\hline
\end{tabular}




\begin{tabular}{|l|l|l|}
\hline $\begin{array}{l}\text { Kenisbian } \\
\text { kebudayaan }\end{array}$ & $\begin{array}{l}\text { Moralitas bersifat nisbi } \\
\text { secara cultural }\end{array}$ & $\begin{array}{l}\text { Nilai-nilai moral dalam } \\
\text { tahapan perkembangan } \\
\text { bersifat universal }\end{array}$ \\
\hline $\begin{array}{l}\text { Pelaku } \\
\text { sosialisasi }\end{array}$ & $\begin{array}{l}\text { Model-model dan } \\
\text { idola yang sangat } \\
\text { berpengaruh, orang- } \\
\text { orang dewasa dan } \\
\text { teman-teman yang } \\
\text { dapat menyalurkan } \\
\text { ganjaran dan hukuman }\end{array}$ & $\begin{array}{l}\text { Orang-orang yang berada } \\
\text { pada tahap perkembangan } \\
\text { yang lebih tinggi dan } \\
\text { memiliki pengaruh yang } \\
\text { sangat besar }\end{array}$ \\
\hline $\begin{array}{l}\text { Implikasi untuk } \\
\text { pendidikan }\end{array}$ & $\begin{array}{l}\text { Orang tua, guru, } \\
\text { teman, dan insane } \\
\text { film harus menjadi } \\
\text { teladan yang baik } \\
\text { dan mengganjar } \\
\text { setiap perilaku siswa } \\
\text { yang memadai }\end{array}$ & $\begin{array}{l}\text { Guru harus berusaha } \\
\text { merangsang dan } \\
\text { menstimulus siswa agar } \\
\text { agar mencapai tahap } \\
\text { perkembangan selanjutnya, } \\
\text { dan menjelaskan ciri-ciri } \\
\text { perilaku moral pada tahap } \\
\text { tersebut. }\end{array}$ \\
\hline
\end{tabular}

\section{Pendidikan Nilai Moral}

- Fenomena Tingkah Laku Amoral Remaja

Kita seringkali menyaksikan di banyak mass media elektronik dan cetak, fenomena tingkah laku amoral remaja yang semakin hari semakin meningkat, dari tindakan amoral yang paling ringan, seperti: membohong, menipu, perilaku menyontek di sekolah, tidak menaati peraturan, mélanggar norma, mencaci maki, sampai pada tingkat yang paling menghawatirkan, mencemaskan dan meresahkan orang tua dan masyarakat, bahkan mengganggu ketertiban umum, kenyamanan, ketentraman, dan kesejahteraan, serta merusak fasilitas umum, seperti: mencuri, menodong/merampok, menjambret, memukul, tawuran pelajar, tindak kekerasan, kriminal, mabuk, dan bahkan sampai membunuh, serta mutilasi. Pendek kata perilaku amoral ini mengancam keselamatan fisik dan jiwa diri mereka dan orang lain.

Pada tataran akademi di jenjang SMP seringkali terjadi tawuran antar pelajar, pada jenjang SMA tawuran pelajar frekuensinya meningkat, 
dari saling mengejek dan mencaci, saling lempar batu, saling memukul, dan bahkan menggunakan senjata tajam sehinggs seringkali terjadi saling bunuh, sehingga pada jenjang ini mereka mendapatkan julukan "SMA tawuran". Pada gilirannya di tingkat Perguruan Tinggi mereka bertambah agresif dan pemberani, mereka menjadi pendemo yang tangguh, tidak hanya lawan sebaya sesama mahasiswa yang dijadikan musuh, tetapi aparat pun dilawan, bahkan berani mencaci maki para pejabat, dan pemimpin Negara walaupun nyawa menjadi taruhannya, mereka nyaris tidak pernah takut. Padahal lawan mereka adalah orangorang yang seharusnya mereka tolong, hormati, hargai, dan segani. Seperti yang kita saksikan di TV dan Koran hampir setiap hari terjadi demo dan bentrokan mahasiswa dengan aparat Negara.

Perilaku amoral, tawuran kolektif, menurut Gustve le Bon dalam bukunya The Crowd, identik dengan irasionalitas, emosionalitas, dan peniruan individu. Perilaku seperti ini berawal dari sharing nilai atau penyebaran isu, kemudian kumpulan individu tersebut frustasi dan akhirnya melakukan tindakan anarkis. Faktor-faktor ini bisa menjadi penyebab terjadinya konflik yang dapat menimbulkan kerusuhan sosial “ ujar Imam B. Pasojo, sosiolog dari UI.

- Kondisi Ideal Remaja sebagai Generasi Penerus

Remaja sebagai generasi penerus bangsa memiliki peran dan posisi yang strategis. Mereka merupakan harapan masa depan bangsa. Maju atau mundurnya bangsa dan Negara ada di pundak mereka. Kalau mereka maju maka majulah Negara, tetapi kalau meraka bobrok, mundur, dan loyo, maka mundurlah Negara. Sudut pandang psikologi para remaja sebagai generasi penerus memiliki potensi yang bisa dikembangkan secara maksimal. Potensi mereka yang prospektif, dinamis, energik, penuh vitalitas, patriotisme dan idealisme harus dikembangkan melalui pendidikan dan pelatihan yang terrencana dan terprogram.

Remaja sebagai generasi penerus juga memiliki kemapuan potensial yang bisa diolah menjadi kemampuan aktual. Selain itu juga memiliki potensi kecerdasan intelektual, emosi dan sosial, berbahasa, dan kecerdasan seni yang bisa diolah menjadi kecerdasan aktual yang dapat membawa mereka kepada prestasi yang tinggi dan kesuksesan. Mereka memiliki potensi moral yang dapat diolah dan dikembangkan menjadi moral yang 
positif sehingga mampu berpartisipasi aktif dalam pembangunan bangsa dan Negara yang penuh dengan kejujuran, tidak korup, semangat yang tinggi dan bertanggungjawab. Potensi mereka yang prospektif, dinamis, energik, penuh vitalitas, patriotisme dan idealisme telah dibuktikan ketika zaman pergerakan nasional, pemuda pelajar telah banyak memberikan kontribusi dalam kehidupan berbangsa dan bernegara.

Hal itu bisa terwujud apabila semua potensi mereka dikembangkan dan salah satunya adalah potensi moral. Oleh karena itu, remaja sebagai generasi penerus harus diselamatkan melalui pendidikan nilai moral. Sehingga harkat dan martabat bangsa bisa terangkat. Kualitas hidup meningkat, dan kesejahteraan serta kenyamanan pun bisa didapat.

\section{Pendidikan Nilai Moral dan Implikasinya}

Melihat dan memperhatikan fenomena dan kondisi ideal remaja sebagai generasi penerus, maka pendidikan nilai moral perlu ditanamkan sejak dini dan harus dikelola secara serius. Dilaksanakan dengan perencanaan yang matang dan program yang berkualitas. Misalnya dengan jumlah jam pelajaran yang memadai, program yang jelas, teknik dan pendekatan proses pembelajaran yang handal serta fasilitas yang memadai. Jika hal ini bisa dilaksanakan dengan baik, niscaya generasi akan memiliki moral yang baik, akhlak mulia, budi pekerti yang luhur, empati, dan tanggungjawab. Sehingga yang kita saksikan bukan lagi kekerasan dan tawuran, melainkan saling membantu, menolong sesama, saling menyayangi, rasa empati, jujur dan tidak korup, serta tanggungjawab. Jangankan memukul atau membunuh, mengejek, mengeluarkan kata-kata kotor dan menghina teman pun tidak boleh karena dinilai sebagai melanggar nilai-nilai moral.

Uraian tersebut menggambarkan betapa pentingnya pendidikan nilai moral bagi generasi penerus bangsa yang tercinta ini. Permasalahannya adalah kapan hal ini bisa kita lakukan? Sekarang? Besok? Atau besok lagi? Kadangkala yang terjadi di masyarakat kita malah sebaliknya. Sejak dini anak sudah kita ajari dan kita didik tidak jujur, tidak percaya diri. Sadar atau tidak kita sebenarnya telah melakukan kesalahan yang sangat merugikan anak. Misalnya ketika anak kita terbentur meja, kita katakana meja nakal, meja yang salah, sambil kita memukuli meja. Ini berarti anak telah kita ajari tidak jujur pada dirinya, dan selalu menyalahkan orang lain 
di luar dirinya, sehingga tertanam pada diri anak bahwa semua yang di luar dirinya adalah salah.

Kalau itu terus berkembang, satu saat nanti ketika dia menjadi mahasiswa atau pejabat, dia akan menjadi manusia yang selalu menyalahkan orang lain, dan tidak pernah merasa dirinya yang bersalah dan harus meminta maaf. Bahkan yang terjadi adalah mencaci orang lain, menyalahkan orang lain walaupun kenyataannya orang lain lebih pintar dari dirinya. Pejabat pun mereka caci maki, bahkan presiden pun mereka caci maki.

Teori pembelajaran sosial dari Bandura dapat dipahami bahwa perilaku anti sosial dan amoral, seperti yang ditayangkan di media elektronika dan cetak akan menjadi idola dan contoh yang sangat mudah dan cepat ditiru dan diadopsi oleh anak. Hal ini sangat berbahaya. Seperti tayangan yang jelas-jelas merupakan film kekerasan setingakat anak TK yang dipoles dengan humor. Film eksen yang penuh adegan perkelahian, darah, dan pembunuhan yang dengan mudah dapat diakses oleh anak dan para generasi muda penerus bangsa. Semua itu akan memicu tindak amoral dan kekerasan di kalangan anak-anak dan remaja. Seperti dikatakan oleh Bandura, "bahwa dalam kehidupan sehari-hari individu menghadapi berbagai jenis stimulus model, yakni model hidup (seperti: bintang film, guru, orang tua, dan teman sebaya) dan model lambing adalah perwujudan tingkah laku dalam gambar, seperti: film, TV, dan media cetak lainnya.

\section{Kesimpulan dan Saran}

\section{Kesimpulan:}

- Pedidikan nilai moral/agama sangat penting bagi para remaja sebagai generasi penerus bangsa, agar martabat bangsa terangkat, kualitas hidup meningkat, kehidupan menjadi lebih baik, aman dan nyaman serta sejahtera.

- Kondisi faktual pendidikan nilai moral/agama di Indonesia dari tahun 1968 sampai saat ini masih terabaikan, belum ditangani secara terencana dan serius. Hal ini terbukti adanya jumlah jam pelajaran yang bernuansa pendidikan agama dan budi pekerti sangat minim, yaitu hanya 2 sampai 4 jam perminggu dari jumlah jam 34 sampai 42 jam perminggu. Padahal dengan KTSP sebenarnya lebih bisa diatur, sehingga kebutuhan ini bisa terakomodasi dan terpenuhi. 
- Fenomena perilaku amoral remaja saat ini sangat mencemaskan dan meresahkan, bahkan telah mengganggu ketertiban umum dan membuat kehidupan tidak aman serta nyaman. Kalau hal ini tidak segera ditangani secara serius dan terencana yaitu dengan pendidikan nilai moral/agama, kemungkinan besar bangsa ini akan kehilangan generasi penerus.

- Kondisi ideal remaja sebagai generasi penerus, merupakan individu yang sedang berkembang, dan oleh karena itu perlu diberi kesempatan berkembang secara proporsional dan terarah, dan mendapatkan layanan pendidikan yang berimbang antara pengetahuan umum dan pendidikan nilai moral/agama. Mereka memiliki peran dan posisi strategis dalam kelangsungan kehidupan berbangsa dan bernegara.

- Pada hakekatnya pelaksanaan pendidikan nilai moral telah lama ada dan telah didukung oleh teori yang handal. Pelaksanaan pendidikan nilai moral/agama dapat mengacu pada teori perkembangan moral versi Kohlberg atau Bandura.

- Ruang lingkup materi pendidikan nilai moral antara lain meliputi: ke-Tuhanan, budi pekerti luhur, akhlak mulia, baik-buruk, benarsalah, kepedulian dan empati, kerjasama, suka menolong, berani, keteguhan hati, adil, kejujufran dan integritas, humor, mandiri dan percaya diri, loyalitas, sabar, rasa bangga, banyak akal, sikap respek, toleransi, ketaatan, penuh perhatian, komitmen, tahu berterima kasih dan tanggungjawab.

- Orang tua, guru, teman sebaya yang menjadi idola, para actor film/ sinetron hendaknya menjadi contoh teladan perilaku yang baik dan mencerminkan tingkah laku yang mengandung nilai-nilai moral yang baik.

\section{Saran}

- Ditujukan terutama kepada pembuat kebijakan, agar pendidikan nilai moral/pendidikan agama ini segera mendapat perhatian, segera ditata kembali agar berfungsi secara proporsional dan dilakukan secara professional, terencana, terprogram, dan terarah. Pendidikan nilai moral hendaknya dapat dimasukkan ke dalam sistem 
Pendidikan Nasional. Mengingat pendidikan nilai moral ini sangat penting bagi kelangsungan hidup para generasi penerus bangsa. Tanpa pendidikan nilai moral kemungkinan besar bangsa dan Negara ini akan terus terpuruk dengan seribu satu permasalahan yang akan muncul.

- Para pendidik dan psikolog serta agamawan hendaklah menjalin kerjasama yang kondusif demi terlaksananya pendidikan nilai moral yang proporsional dan professional di semua jenjang pendidikan.

- Para anggota legeslatif diharapkan lebih proaktif dalam ikut serta terlaksanya pendidikan nilai moral ini. Pendidikan nilai moral perlu diperjuangkan di tingkat parlemen agar segera dapat terealisir.

\section{Daftar Pustaka}

Majid, Abdul., A.A. (2001). Mendidik dengan Cerita. 30 cerita pilihan. Bandung: P.T. Remaja Rosda Karya

Allen, Bem P. (1990). Personal Adjusment. Wodsworth, California: Belmont Inc.

Bandura, A., \& Walter, R.H. (1973). Social Learning Theory and Personality Development. New York: Holt Rinehart and Winston

Cronbach, L.J. (1977). Educational Psychology, 3 edition, Harcourt Brace Javanovich, Inc.

Calhoun, F. James, \& Acoclla J. R. Alih bahasa R.S. Satmoko. (1990). Psikologi tentang Penyesuaian dan Hubungan Kemanusiaan. Edisi ketiga, IKIP Semarang Press

Darling, N. (1999). Parenting Style and Its Correlates. Eric Degest. Champaign IL: ERIC Clearinghouse on elementary and Early Chilhood Education. (online)Tersedia: ttp://www.ed.gov/ databases/ERIC_Digest/ed427896.html

Fraenkel, Jack R. (1977). How to Teach About Values: An Analytik Approach. Enflewood Cliffs, New Jersedy: Prentice Hall, Inc.

Larry Winecoff, H. (1998). Values Education, conceps and Models, Bandung: Depdikbud. PPs, IKIP 
Kniker, Charles R. (1977). You And Values Education. Iowa State University. Columbus, Ohio: Charles E. Merrill Publishing Compeny, A Bell \& howell Company

Kregman, J.J \& Worchel, P. (1961). Arbitrarines of Frustration and Agression. Journal of Abnormal and social Psychology 63

Schiller, P. \& Bryant, T. (2002). Values Book for Chilren, 16 Moral Dasar Bagi Anak, disertai kegiatan yang bisa diolakukan orang tua bersama anak, Jakarta: PT Elex Mesia Komputindo, kelompok Gramedia

Syah, M. (2002). Pengantar: Utami Munandar. Psikilogi Belajar. Jakarta: Logos Wacana Ilmu dan Pemikiran 